\title{
Surface morphology and deuterium retention in tungsten oxide layers exposed to low- energy, high flux D plasma
}

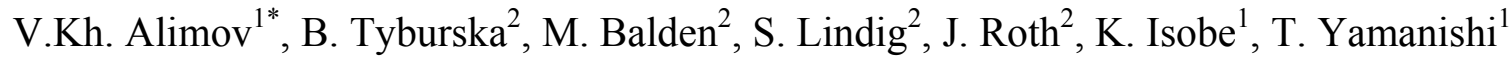 \\ ${ }^{1}$ Tritium Technology Group, Japan Atomic Energy Agency, Tokai, Ibaraki, 319-1195, Japan \\ ${ }^{2}$ Max-Planck-Institut für Plasmaphysik, EURATOM Association, D-85748 Garching, Germany
}

\begin{abstract}
Surface morphology and deuterium retention in tungsten oxide layers $\left(\mathrm{WO}_{3-\mathrm{z}}\right.$, $z \leq 0.25$ ) grown on polycrystalline and recrystallized $W$ substrates have been examined after exposure to a low-energy (38 eV/D), high flux $\left(10^{22} \mathrm{D} / \mathrm{m}^{2} \mathrm{~s}\right) \mathrm{D}$ plasma to an ion fluence of $10^{26} \mathrm{D} / \mathrm{m}^{2}$ at various temperatures (up to $\sim 700 \mathrm{~K}$ ). Characterization methods used were scanning electron microscopy, X-ray diffraction, Rutherford backscattering spectroscopy, and the $\mathrm{D}\left({ }^{3} \mathrm{He}, \mathrm{p}\right)^{4} \mathrm{He}$ nuclear reaction analysis. During exposure to the $\mathrm{D}$ plasma at temperatures of $340-615 \mathrm{~K}$, a partial reduction of the tungsten oxide takes place in the near-surface layer up to $0.3 \mu \mathrm{m}$ in depth. Even at around room temperature, deuterium atoms diffuse several micrometers into the tungsten oxide. The high D concentration of about $0.1 \mathrm{D} / \mathrm{W}$ observed in the first micrometers below the surface at temperatures below $500 \mathrm{~K}$ can be related mainly to $\mathrm{D}$ atoms chemically bonded to $\mathrm{O}$ atoms. As the exposure temperature increases, the D concentration decreases, reaching about $2 \times 10^{-4} \mathrm{D} / \mathrm{W}$ at $615 \mathrm{~K}$. At plasma exposure temperatures of about $700 \mathrm{~K}$, the oxide layer shrinks and loses a large fraction of oxygen.
\end{abstract}

PACS numbers: 52.40.Hf, 61.72.Qq, 61.80.Jh

JNM keywords: Oxides, Plasma-Materials Interaction; Tungsten, Tungsten Alloys and Compounds

*Corresponding author. Tel.: +81 29282 6452; fax: +81292825917.

E-mail address: alimov.vladimir@jaea.go.jp (V.Kh. Alimov). 


\section{Introduction}

Due to its favorable physical properties, such as low erosion yield and high melting temperature, tungsten (W) is a candidate material for plasma-facing high heat-flux structures in fusion reactors in operation and under construction, such as the tokamaks ASDEX-Upgrade [1], ITER [2], QUEST [3], and DEMO [4]. Oxide layers exist naturally on the $\mathrm{W}$ surfaces as a result of the strong chemical affinity of this metal to oxygen. Furthermore, oxide layers can be formed due to the proposed $\mathrm{O}_{2}$ gas introduction into the reactor chamber for tritium removal from carbon deposits [5]. The presence of the oxide layer on the surface causes a considerable decrease (approximately by a factor of 10 ) of the threshold energy for the sputtering of $\mathrm{W}$ bombarded with hydrogen isotopes, because of the reduction of the binding energy of tungsten oxide molecules [6]. There is some data indicating that deuterium retention in tungsten oxide layers is higher than in $\mathrm{W}[7,8,9]$. Hydrogen concentration of $0.4 \mathrm{H} / \mathrm{W}$ (9 at.\%) in amorphous $\mathrm{WO}_{3}$ films covered by a $\mathrm{W}$ layer was reported after irradiation with $10 \mathrm{keV} \mathrm{H}_{2}{ }^{+}$ions at room temperature [10]. In this context, additional data on the behavior of hydrogen isotopes in tungsten oxides, particularly under exposure to low-energy D plasma at various temperatures, is important to estimate tritium uptake and retention in fusion reactor components.

The oxidation of tungsten is thermodynamically favored and the formation of $\mathrm{WO}_{3}$ is more favored than the formation of $\mathrm{WO}_{2}$. The oxidation of $\mathrm{W}$ depends strongly on the temperature. At room temperature small amounts of tungsten oxide are formed on the surface due to the contact with air [11]. Above $600 \mathrm{~K}$, a thin dark blue layer of $\mathrm{WO}_{2.75}$ becomes visible. Above $850 \mathrm{~K}$, yellow $\mathrm{WO}_{3}$ forms on the layer of dark blue oxide. Above $1250 \mathrm{~K}$, the volatility of $\mathrm{WO}_{3}$ becomes noticeable, and lastly, the tungsten surface remains free of thick oxide film above $1550 \mathrm{~K}$ because the oxide volatilizes as quickly as it is formed [11].

The tungsten trioxide $\mathrm{WO}_{3}$ is one of the most commonly investigated tungsten oxides. Its open crystal structure allows the formation of compounds known as the hydrogen tungsten bronze $\left(\mathrm{H}_{x} \mathrm{WO}_{3}, x \leq 1\right)[12,13]$. The analogous hydrogen bronze is best described as a nonstoichiometric oxide hydroxide, $\mathrm{WO}_{3-x}(\mathrm{OH})_{x}$ [13]. The hydrogen bronzes are easily oxidized to $\mathrm{WO}_{3}$ and $\mathrm{H}_{2}$ at room temperature by air, $\mathrm{H}_{2} \mathrm{O}$, and other oxidizing agents [14]. At room temperature the hydrogen diffusivity in the amorphous oxide layers is found to be in the range of $1.8 \times 10^{-14}$ to $2.5 \times 10^{-11} \mathrm{~m}^{2} / \mathrm{s}[15,16,17,18,19]$, whereas for the crystalline layer this value becomes $(1.4-3) \times 10^{-15} \mathrm{~m}^{2} / \mathrm{s}[17,20]$. 
The reduction of $\mathrm{WO}_{3}$ by $\mathrm{H}_{2}$ is known to start at about $670 \mathrm{~K}$ ( $\left.T_{\text {reduce }}\right)$. The course of the reduction is dependent on many factors, particularly on the presence of $\mathrm{H}_{2} \mathrm{O}$ and catalysts [21]. Salje et al. [22] found that the tungsten oxidation state was reduced after $\mathrm{H}^{+}$ and $\mathrm{Ar}^{+}$bombardment and concluded that $\mathrm{Ar}^{+}$bombardment of $\mathrm{WO}_{3}$ preferentially removes oxygen atoms and that $\mathrm{H}^{+}$bombardment causes direct formation of $\mathrm{H}_{x} \mathrm{WO}_{3}$. On the other hand, Bringans et al. [12, 23], studying the effect of $\mathrm{H}^{+}$bombardment on $\mathrm{WO}_{3}$ by the ultraviolet photoemission spectroscopy, postulated that a loss of oxygen atoms from the surface rather than formation of $\mathrm{H}_{x} \mathrm{WO}_{3}$ was the paramount effect.

The aim of the present work lies in obtaining data on deuterium concentration in tungsten oxide exposed to low-energy, high flux D plasma at various temperatures and determining the oxygen loss.

\section{Experimental procedures}

Two types of tungsten produced by A.L.M.T. Corp., Japan (each with a purity of 99.99 wt.\%) were used as substrates for growing of oxide layers - (i) a polycrystalline ITER-grade tungsten (pc-ITER-W) where the grain elongation is perpendicular to the surface [24] and grain size is around $1 \mu \mathrm{m}$, and (ii) polycrystalline tungsten fully recrystallized at $2070 \mathrm{~K}$ for 1 hour after cutting and polishing (rc-W) with grains of 20-200 $\mu \mathrm{m}$. Plates of the $\mathrm{W}$ materials, $10 \times 10 \times 2 \mathrm{~mm}^{3}$ in size, were oxidized by annealing in air for 10 minutes. Two runs of the annealing were performed - the pc-ITER-W plates were oxidized at $T_{\text {oxy }} \approx 820 \mathrm{~K}$, whereas the rc-W plates were oxidized at $T_{\text {oxy }} \approx 870 \mathrm{~K}$.

The phase of the oxide layers was examined by X-ray diffraction (XRD) (3003-PTS, Seifert). The diffractograms were obtained with a parallel beam configuration as $\theta / 2 \theta$ scans and under grazing incidence. Additionally, for the most intense XRD peaks, a texture analysis was performed.

The surface topography was examined by scanning electron microscopy (SEM) (Real Surface View Microscope, KEYENCE VE-9800) at a tilt angle of $45^{\circ}$, whereas the oxide layer morphology of the plasma-exposed samples was analyzed by a SEM combined with a focused ion beam (FIB) (HELIOS NanoLab 600, FEI) [25].

The oxide layers formed on the $\mathrm{W}$ substrates were exposed to a deuterium plasma beam consisting to over $80 \%$ of incident $\mathrm{D}_{2}^{+}$ions. The plasma was generated in the Linear Plasma Generator [26]. A bias voltage of $-80 \mathrm{~V}$ was applied to the sample resulting in an incident energy of $38 \mathrm{eV} / \mathrm{D}$, taking into account the plasma potential of about $-4 \mathrm{~V}$ as 
measured by a Langmuir probe. The incident deuterium ion flux was fixed at $10^{22} \mathrm{D} / \mathrm{m}^{2} \mathrm{~s}$. The samples were passively heated by the plasma itself, and the exposure temperature was set in the range from 340 to $705 \mathrm{~K}$ by varying the thermal contact between the sample and the cooled holder. All samples were exposed to an ion fluence of $1 \times 10^{26} \mathrm{D} / \mathrm{m}^{2}$.

The D concentration within the near-surface layer was measured by means of the $\mathrm{D}\left({ }^{3} \mathrm{He}, \alpha\right) \mathrm{H}$ reaction at a ${ }^{3} \mathrm{He}$ energy of $0.69 \mathrm{MeV}$, and the $\alpha$ particles were energyanalyzed with a small solid-angle surface barrier detector at a laboratory scattering angle of $102^{\circ}$. The $\alpha$ spectrum was transformed into a $\mathrm{D}$ depth profile up to a depth of about $10^{23}$ atoms $/ \mathrm{m}^{2}$ using the SIMNRA program [27]. To determine the D concentration at larger depths, an analyzing beam of ${ }^{3} \mathrm{He}$ ions with energies varying from 0.69 to $4 \mathrm{MeV}$ was used. The protons from the $\mathrm{D}\left({ }^{3} \mathrm{He}, \mathrm{p}\right)^{4} \mathrm{He}$ nuclear reaction were counted using a wide-angle proton detector placed at an angle of $135^{\circ}$. The proton yields measured at different ${ }^{3} \mathrm{He}$ ion energies allowed measuring the $\mathrm{D}$ depth profile at depths of up to $5 \times 10^{23}$ atoms $/ \mathrm{m}^{2}$ (i.e., 7 $\mu \mathrm{m}$ for metallic W) $[28,29]$.

The $\mathrm{W}$ concentration in the oxide layers before and after exposure to the D plasma was determined by means of Rutherford backscattering spectroscopy (RBS) at ${ }^{3} \mathrm{He}$ ion energies of 2.8 and $3.6 \mathrm{MeV}$ and evaluated with SIMNRA. The backscattered ${ }^{3} \mathrm{He}$ was energy-analyzed at a scattering angle of $165^{\circ}$ by a small-angle surface barrier detector. The $\mathrm{W}$ concentration was determined up to a depth of $2 \times 10^{23}$ atoms $/ \mathrm{m}^{2}$ with an accuracy of 1 at. $\%$.

\section{Results and discussion}

According to the RBS data (Fig. 1a), the composition of the grown oxide layers corresponds to stoichiometric $\mathrm{WO}_{3}$ with 25 at.\% of $\mathrm{W}$ atoms. On the other hand, the dark blue colour of the oxide layers is indicative of the $\mathrm{WO}_{2.75}$ phase (26.7 at.\% of $\mathrm{W}$ atoms). It should be noted that the phase identification by XRD is hindered by a strong fibre texture of the oxide layers grown on both W substrates. Nevertheless, the oxide layers can be attributed to the $\mathrm{WO}_{3}$ phase with the (020) planes parallel to the surface. The broad width of the diffraction peaks indicates that the crystallites are small or strongly disordered. However, it seems plausible that the grown oxide involves two phases, $\mathrm{WO}_{3}$ and $\mathrm{WO}_{2.75}$ [30], therefore below we will denote the grown tungsten oxide as $\mathrm{WO}_{3-\mathrm{z}}$, where $0 \leq z \leq 0.25$. 
A thickness of the oxide layers formed on the surface of the pc-ITER-W is about $8 \times 10^{22}$ atoms $/ \mathrm{m}^{2}$, whereas for the $\mathrm{rc}-\mathrm{W}$ the oxide thickness is above $2 \times 10^{23}$ atoms $/ \mathrm{m}^{2}$. Taking into account the $\mathrm{WO}_{3}$ atomic density, $N_{\mathrm{wO}_{3}}=7.5 \times 10^{28}(\mathrm{~W}+\mathrm{O}) / \mathrm{m}^{3}$, the observable depth of the oxide layers in the RBS is assessed to be about $1 \mu \mathrm{m}$ for the $\mathrm{WO}_{3-z} / \mathrm{pc}$-ITER$\mathrm{W}\left(T_{\text {oxy }} \approx 820 \mathrm{~K}\right)$ and above $2.5 \mu \mathrm{m}$ for the $\mathrm{WO}_{3-\mathrm{z}} / \mathrm{rc}-\mathrm{W}\left(T_{\text {oxy }} \approx 870 \mathrm{~K}\right)$.

The surface morphology of the oxide layers corresponds mainly to the grain structure of $\mathrm{W}$ substrates (see Figs. 2a and 3a). The thickness of the oxide layer on the rc-W is ranging from 3 to $10 \mu \mathrm{m}$ (Fig. 4a) and varies from grain to grain due to dependency of the oxidation rate on the grain orientation. The different growth rates on the individual grains cause crack formation along the grain boundaries (see Figs $2 \mathrm{a}$ and $4 \mathrm{a}$ ). However, similar cracks are not observed on the surface of the oxide layers grown on the pc-ITER-W (see Fig. 3a), probably due to smaller oxide thickness or due to strongly distorted grains at the surface by the mechanical preparation treatment. Note the oxidation of tungsten leads to a volume increase by a factor of three.

After exposure to $\mathrm{D}$ plasma at temperatures $T_{\exp }=340-515 \mathrm{~K}$, the surface morphology of the oxide layers grown on both types of $\mathrm{W}$ substrates, exhibits the growth of the cracks in length, and additional cracks appear across the grain surface (see Figs. $2 b$ and $3 \mathrm{~b}$ ). At $T_{\exp }=615-705 \mathrm{~K}$, the density of the intragranular cracks increases (Figs. 2c,d and $3 \mathrm{c}, \mathrm{d})$. A peculiarity of the oxide layers exposed at temperatures of about $700 \mathrm{~K}$ is a strong roughening and an assumed decrease of the oxide thickness (Fig. 2d).

It follows from the RBS spectra (Fig. 1b) that exposure of the oxide layers to the D plasma at $T_{\exp }=340-515 \mathrm{~K}$ leads to an increase in the $\mathrm{W}$ concentration to $35-40$ at. $\%$ on the surface with following decrease down to about 25 at.\% within a layer of about $1 \times 10^{22}$ atoms $/ \mathrm{m}^{2}(0.13 \mu \mathrm{m})$ in thickness (see Fig. 5a). However, at an exposure temperature of $605-615 \mathrm{~K}$, the $\mathrm{W}$ concentration increases to $50-60$ at. $\%$ within the near-surface layer of about $2.5 \times 10^{22}$ atoms $/ \mathrm{m}^{2}(0.33 \mu \mathrm{m})$ in thickness. This layer on the $\mathrm{rc}-\mathrm{W}$ was observed directly by SEM combined with FIB cross-sectioning (Fig. 4b), and the reduction of the oxygen content in this layer was confirmed by energy-dispersive X-ray spectroscopy. Its geometrical thickness is $0.32 \mu \mathrm{m}$. Clearly, a partial reduction of the tungsten oxide takes place in the near-surface layer during the plasma exposure. It should be noted that the D ion implantation range is only about $3 \mathrm{~nm}$ [31].

A significant increase of the $\mathrm{W}$ concentration over the whole thickness of the oxide layer on the rc-W is observed during plasma exposure at $T_{\exp }=705 \mathrm{~K}$ (RBS spectrum is shown in Fig. 1b, whereas the tungsten depth profile is depicted in Fig. 5a). This 
temperature is above the onset temperature $T_{\text {reduce }} \approx 670 \mathrm{~K}$ for reduction of $\mathrm{WO}_{3}$ by hydrogen gas [21], and it is reasonable to suggest that the increase of the $\mathrm{W}$ concentration to $50-70$ at.\% is due to the reduction of $\mathrm{WO}_{3-z}$ by $\mathrm{D}$ atoms implanted in the near-surface layer and diffusing into the bulk. At this exposure temperature, oxygen atoms are removed from the oxide layer in the form of water molecules [32], and, as may be inferred from the RBS spectrum (see Fig. 1b) and the SEM pictures (see Fig. 2d), the layer becomes thinner, as a consequence. However, the oxygen-free metallic tungsten is not completely restored.

RBS spectra highlight another important features of the oxide layers exposed to the D plasma at temperatures below the onset temperature for the oxide reduction $\left(T_{\text {reduce }} \approx\right.$ $670 \mathrm{~K}$ ): (i) a significant increase of the $\mathrm{W}$ concentration over the whole thickness of the oxide layer on the pc-ITER-W at $T_{\exp }=605 \mathrm{~K}$ (Fig. 6a); (ii) an increase of the $\mathrm{W}$ concentration at depths of $1-3 \mu \mathrm{m}$ from 25 to 28 at.\% after exposure at temperature of $515 \mathrm{~K}$, and the increase to $45 \%$ at $615 \mathrm{~K}$ for the oxide layers on the rc-W (Fig. 5a). It seems likely that the process of the oxide reduction by diffusing $\mathrm{D}$ atoms occurs at a low rate already at temperatures lower than those considered before.

After D plasma exposure at temperatures up to $430 \mathrm{~K}$, the deuterium concentration in the tungsten oxide matrix at depths beyond the oxygen depleted layer up to $1-2 \mu \mathrm{m}$ is $2-3$ at.\% (Figs. $5 \mathrm{~b}$ and $6 \mathrm{~b}$ ). The D concentration in the near-surface layer is somewhat lower than that in the $\mathrm{WO}_{3-z}$ matrix, probably due to a partial reduction of the tungsten oxide. As the exposure temperature increases, the $\mathrm{D}$ concentration in the oxide matrix decreases, reaching about $5 \times 10^{-3}$ at. $\%$ at $T_{\exp }=615 \mathrm{~K}$ for $\mathrm{WO}_{3-\mathrm{z}} / \mathrm{rc}-\mathrm{W}$ (Fig. $5 \mathrm{~b}$ ), while for $\mathrm{WO}_{3-\mathrm{z}} / \mathrm{pc}-$ ITER-W it stays just above $10^{-2}$ at. $\%$ at $T_{\exp }=605 \mathrm{~K}$ (Fig. $6 \mathrm{~b}$ ). For the $\mathrm{WO}_{3-\mathrm{z}} / \mathrm{rc}-\mathrm{W}$ exposed at temperature of $705 \mathrm{~K}$, the oxide thickness shrinks to less than $2 \mu \mathrm{m}$, and the D concentration slightly increases (Fig. 5b). However, it must be emphasized that a strong reduction of $\mathrm{WO}_{3}$ takes place at this temperature.

The maximum concentration of deuterium retained at depths of 0.3-3 $\mu \mathrm{m}$ in the tungsten oxide layers (Figs. $5 \mathrm{~b}$ and $6 \mathrm{~b}$ ) is expressed in units of the D-to-W ratio and plotted in Fig. 7, as function of exposure temperature. For comparison, the maximum D concentration at depths of $2-4 \mu \mathrm{m}$ in metallic re-crystallized $\mathrm{W}$ [33], metallic polycrystalline ITER-grade W [34], and porous (93-96\% of the theoretical density), 200 $\mu \mathrm{m}$ thick vacuum plasma-sprayed (VPS) W coatings [35] exposed in the same experimental equipment to a low-energy $(38 \mathrm{eV} / \mathrm{D})$, high flux D plasma is plotted too. It is apparent that at exposure temperatures up to $550 \mathrm{~K}$, the presence of the oxide structure significantly increases the amount of $\mathrm{D}$ atoms retained per $\mathrm{W}$ atom. 
From the analysis of the D profiles (Figs. $5 b$ and $6 b$ ) it is concluded that deuterium atoms diffuse deeply into the bulk of the tungsten oxide, reaching at least a depth of several micrometers even at $T_{\exp }=340 \mathrm{~K}$, and are captured by traps. The high $\mathrm{D}$ concentration of about $0.1 \mathrm{D} / \mathrm{W}$ at depths far beyond the $\mathrm{D}$ ion implantation range in the $\mathrm{WO}_{3-\mathrm{z}}$ after exposure at temperatures below $500 \mathrm{~K}$ (Fig. 7) can be related to D atoms chemically bonded to $\mathrm{O}$ atoms with the formation of deuterium tungsten bronze $\left(\mathrm{D}_{x} \mathrm{WO}_{3}\right)$ molecules $[12,13]$ and to molecular deuterium accumulated inside closed pores and cracks initially present in the oxide layer [8]. However, in a vacuum plasma-sprayed W (VPS-W) coating with a porosity of $4-7 \%$, the maximum $D$ concentration at depths of $2-4 \mu \mathrm{m}$ does not exceed $0.03 \mathrm{D} / \mathrm{W}$ [35] (Fig. 7). Note that the VPS-W coating is characterized at these depths by closed pores. Consequently, relatively high $\mathrm{D}$ concentration (about $0.1 \mathrm{D} / \mathrm{W}$ ) in the tungsten oxide layers can not be explained by accumulation of molecular deuterium inside pores. It may be concluded that the formation of chemical bonds between $\mathrm{D}$ and $\mathrm{O}$ atoms is responsible for the trapping of the majority of deuterium in the tungsten oxide matrix.

\section{Conclusions}

Surface morphology, composition, and deuterium retention have been studied in tungsten oxide layers $\left(\mathrm{WO}_{3-\mathrm{z}}, 0 \leq \mathrm{z} \leq 0.25\right)$ exposed to a low-energy $(38 \mathrm{eV} / \mathrm{D})$, high flux D plasma $\left(10^{22} \mathrm{D} / \mathrm{m}^{2} \mathrm{~s}\right)$ to an ion fluence of $10^{26} \mathrm{D} / \mathrm{m}^{2}$ at various temperatures.

The surface morphology of the oxide layers grown both on the polycrystalline ITERgrade $\mathrm{W}$ and recrystallized $\mathrm{W}$ corresponds mainly to that of $\mathrm{W}$ substrate materials. The oxide layer on the recrystallized $\mathrm{W}$ exhibits cracks along grain boundaries, since the thickness of the oxide layer varies with the $\mathrm{W}$ grain orientation between 3 and $10 \mu \mathrm{m}$ due to variation of the oxidation rate with grain orientation. After exposure to the D plasma at temperatures of $340-705 \mathrm{~K}$ additional cracks on the grain surface and intragranular cracks appear.

Exposure of the oxide layers on the recrystallized W to the D plasma at $340-615 \mathrm{~K}$ leads to a partial reduction of the tungsten oxide in the near-surface layer up to $0.3 \mu \mathrm{m}$. During plasma exposure at $705 \mathrm{~K}$, this oxide layer becomes thinner due to loss of oxygen by formation of water molecules. The reduction over the whole thickness of the oxide layer on the polycrystalline ITER-grade $\mathrm{W}$ in observed even at $605 \mathrm{~K}$. It may be suggested that the process of the oxide reduction by diffusing $\mathrm{D}$ atoms occurs already at temperatures 
below the onset temperature $T_{\text {reduce }} \approx 670 \mathrm{~K}$ for reduction of $\mathrm{WO}_{3}$ by hydrogen gas considered before.

In the oxide layer exposed to the D plasma, deuterium atoms diffuse into the bulk to depths beyond several micrometers even at a temperature of $340 \mathrm{~K}$. The high $\mathrm{D}$ concentration of about $0.1 \mathrm{D} / \mathrm{W}$ (in units of the D-to-W atomic ratio) observed in the first micrometers below the surface at exposure temperatures below $500 \mathrm{~K}$ can be related mainly to $\mathrm{D}$ atoms chemically bonded to $\mathrm{O}$ atoms with the formation of deuterium tungsten bronze $\left(\mathrm{D}_{x} \mathrm{WO}_{3}\right)$ molecules $[12,13]$. As the exposure temperature increases, the $\mathrm{D}$ concentration decreases, reaching about $2 \times 10^{-4} \mathrm{D} / \mathrm{W}$ at $615 \mathrm{~K}$, due to the oxide reduction.

\section{Acknowledgements}

The authors thank Dr. M. Oyaidzu (JAEA Tokai) for help with the oxidation of W samples and J. Dorner and M. Fußeder (IPP Garching) for technical assistance with the ${ }^{3} \mathrm{He}$ beam analyses. 


\section{Figure captions}

Figure 1. Rutherford backscattering (RBS) spectra for $2.8 \mathrm{MeV}{ }^{3} \mathrm{He}$ ions incident on tungsten oxide layers: (a) as grown on the surface of polycrystalline ITER-grade W and recrystallized $\mathrm{W}$, and (b) grown on the surface of recrystallized $\mathrm{W}(\mathrm{rc}-\mathrm{W})$ and then exposed to a low-energy ( $38 \mathrm{eV} / \mathrm{D})$, high-flux $\left(10^{22} \mathrm{D} / \mathrm{m}^{2} \mathrm{~s}\right) \mathrm{D}$ plasma with an ion fluence of $10^{26} \mathrm{D} / \mathrm{m}^{2}$ at various temperatures. The thick solid and dash lines represent RBS spectra for stoichiometric $\mathrm{WO}_{3}$ and metallic $\mathrm{W}$, respectively, calculated by the SIMNRA program [27].

Figure 2. SEM images of tungsten oxide layers grown on the surface of recrystallized W before (a) and after exposure to a low-energy (38 eV/D), high-flux $\left(10^{22} \mathrm{D} / \mathrm{m}^{2} \mathrm{~s}\right) \mathrm{D}$ plasma with an ion fluence of $10^{26} \mathrm{D} / \mathrm{m}^{2}$ at temperatures of $515 \mathrm{~K}$ (b), $615 \mathrm{~K}$ (c), and $705 \mathrm{~K}$ (d). The magnification of all images is the same.

Figure 3. SEM images of tungsten oxide layers grown on the surface of polycrystalline ITER-grade $\mathrm{W}$ before (a) and after exposure to a low-energy ( $38 \mathrm{eV} / \mathrm{D})$, high-flux $\left(10^{22}\right.$ $\mathrm{D} / \mathrm{m}^{2} \mathrm{~s}$ ) D plasma with an ion fluence of $10^{26} \mathrm{D} / \mathrm{m}^{2}$ at temperatures of $490 \mathrm{~K}(\mathrm{~b}), 605 \mathrm{~K}$ (c), and $700 \mathrm{~K}(\mathrm{~d})$. The magnification of all images is the same.

Figure 4. SEM images of tungsten oxide layers grown on the surface of recrystallized W and exposed to a low-energy (38 eV/D), high-flux $\left(10^{22} \mathrm{D} / \mathrm{m}^{2} \mathrm{~s}\right) \mathrm{D}$ plasma with an ion fluence of $10^{26} \mathrm{D} / \mathrm{m}^{2}$ at temperatures of $340 \mathrm{~K}$ (a) and $615 \mathrm{~K}$ (b). The central part of the images shows a cross-section prepared by FIB ( $-38^{\circ}$ tilted). In the panel (a), the thicknesses of $\mathrm{WO}_{3-z}$ layers on individual $\mathrm{W}$ grains are labelled; the upper and lower part of the image shows the surface $\left(52^{\circ}\right.$ tilted). Note the layer on top of the oxide is an artificial protection coating for preparing the cross-section. In the panel (b), the thicknesses of $\mathrm{WO}_{3-z}$ layer and reduced oxide layer are labelled.

Figure 5. Tungsten (a) and deuterium (b) concentrations in tungsten oxide layers grown on the surface of recrystallized $\mathrm{W}$ and then exposed to a low-energy $(38 \mathrm{eV} / \mathrm{D})$, high-flux $\left(10^{22} \mathrm{D} / \mathrm{m}^{2} \mathrm{~s}\right) \mathrm{D}$ plasma with an ion fluence of $10^{26} \mathrm{D} / \mathrm{m}^{2}$ at various temperatures. The tungsten concentration was determined by RBS, whereas the D concentration was measured by means of the $\mathrm{D}\left({ }^{3} \mathrm{He}, \mathrm{p}\right)^{4} \mathrm{He}$ nuclear reaction. Arrows indicate depths of $0.25,1$, and $3 \mu \mathrm{m}$ for stoichiometric $\mathrm{WO}_{3}$ taking the atomic density of $7.5 \times 10^{28}(\mathrm{~W}+\mathrm{O}) / \mathrm{m}^{3}$. 
Figure 6. Tungsten (a) and deuterium (b) concentrations in tungsten oxide layers grown on the surface of polycrystalline ITER-grade $\mathrm{W}$ and then exposed to a low-energy ( $38 \mathrm{eV} / \mathrm{D})$, high-flux $\left(10^{22} \mathrm{D} / \mathrm{m}^{2} \mathrm{~s}\right) \mathrm{D}$ plasma with an ion fluence of $10^{26} \mathrm{D} / \mathrm{m}^{2}$ at various temperatures. The tungsten concentration was determined by RBS, whereas the D concentration was measured by means of the $\mathrm{D}\left({ }^{3} \mathrm{He}, \mathrm{p}\right)^{4} \mathrm{He}$ nuclear reaction. Arrows indicate depths of $0.25,1$, and $3 \mu \mathrm{m}$ for stoichiometric $\mathrm{WO}_{3}$ taking the atomic density of $7.5 \times 10^{28}(\mathrm{~W}+\mathrm{O}) / \mathrm{m}^{3}$.

Figure 7. Maximum concentration of deuterium retained at a depth of 0.3-3 $\mu \mathrm{m}$ in tungsten oxide, recrystallized W (rc-W) [33], polycrystalline ITER-grade W (pc-ITER-W) [34], and porous vacuum plasma-sprayed W (VPS-W) [35] exposed to a low-energy (38 eV/D), high-flux $\left(10^{22} \mathrm{D} / \mathrm{m}^{2} \mathrm{~s}\right) \mathrm{D}$ plasma, as a function of the exposure temperature. The $\mathrm{D}$ concentration is expressed in units of the D-to-W ratio. The applied D ion fluences, $\Phi$, are indicated in the legend. The $\mathrm{D}$ concentration in the $\mathrm{W}$ materials was taken after D plasma exposure to highest realized D ion fluences just to show maximum D concentration. 


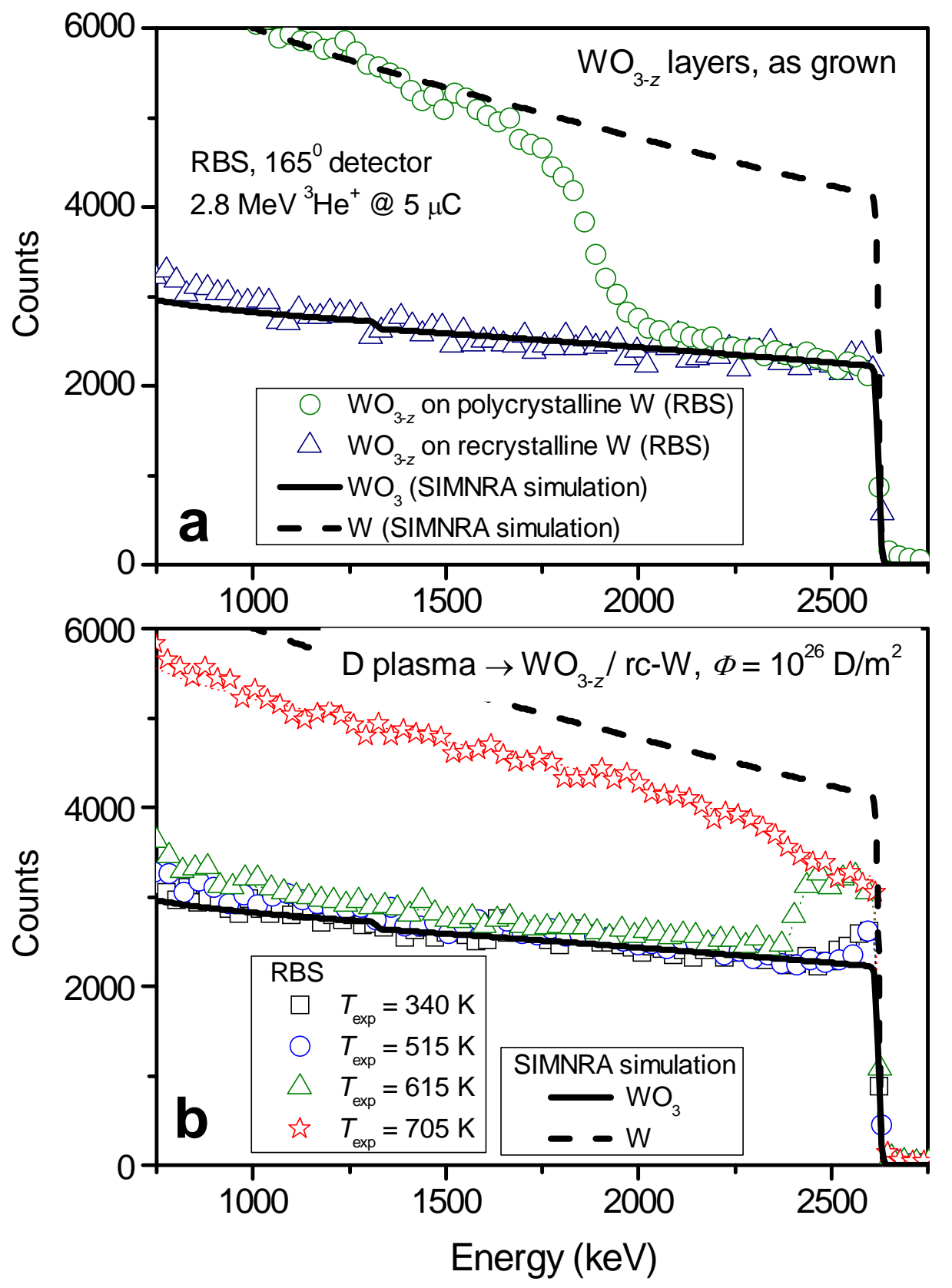

Figure 1. Rutherford backscattering (RBS) spectra for $2.8 \mathrm{MeV}{ }^{3} \mathrm{He}$ ions incident on tungsten oxide layers: (a) as grown on the surface of polycrystalline ITER-grade W and recrystallized $\mathrm{W}$, and (b) grown on the surface of recrystallized $\mathrm{W}(\mathrm{rc}-\mathrm{W})$ and then exposed to a low-energy ( $38 \mathrm{eV} / \mathrm{D})$, high-flux $\left(10^{22} \mathrm{D} / \mathrm{m}^{2} \mathrm{~s}\right) \mathrm{D}$ plasma with an ion fluence of $10^{26} \mathrm{D} / \mathrm{m}^{2}$ at various temperatures. The thick solid and dash lines represent RBS spectra for stoichiometric $\mathrm{WO}_{3}$ and metallic $\mathrm{W}$, respectively, calculated by the SIMNRA program [27]. 


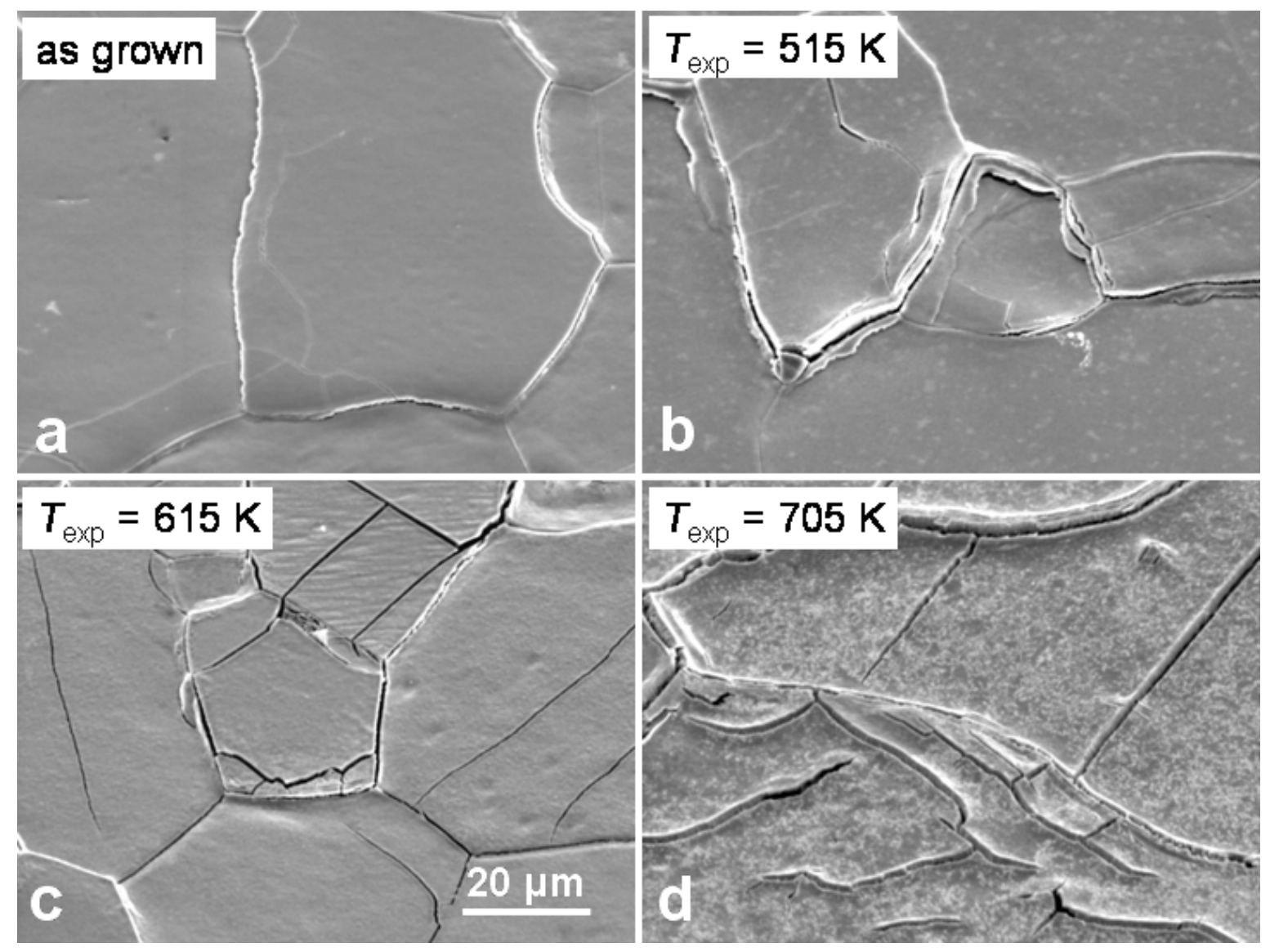

Figure 2. SEM images of tungsten oxide layers grown on the surface of recrystallized W before (a) and after exposure to a low-energy (38 eV/D), high-flux $\left(10^{22} \mathrm{D} / \mathrm{m}^{2} \mathrm{~s}\right) \mathrm{D}$ plasma with an ion fluence of $10^{26} \mathrm{D} / \mathrm{m}^{2}$ at temperatures of $515 \mathrm{~K}(\mathrm{~b}), 615 \mathrm{~K}$ (c), and $705 \mathrm{~K}$ (d). The magnification of all images is the same. 


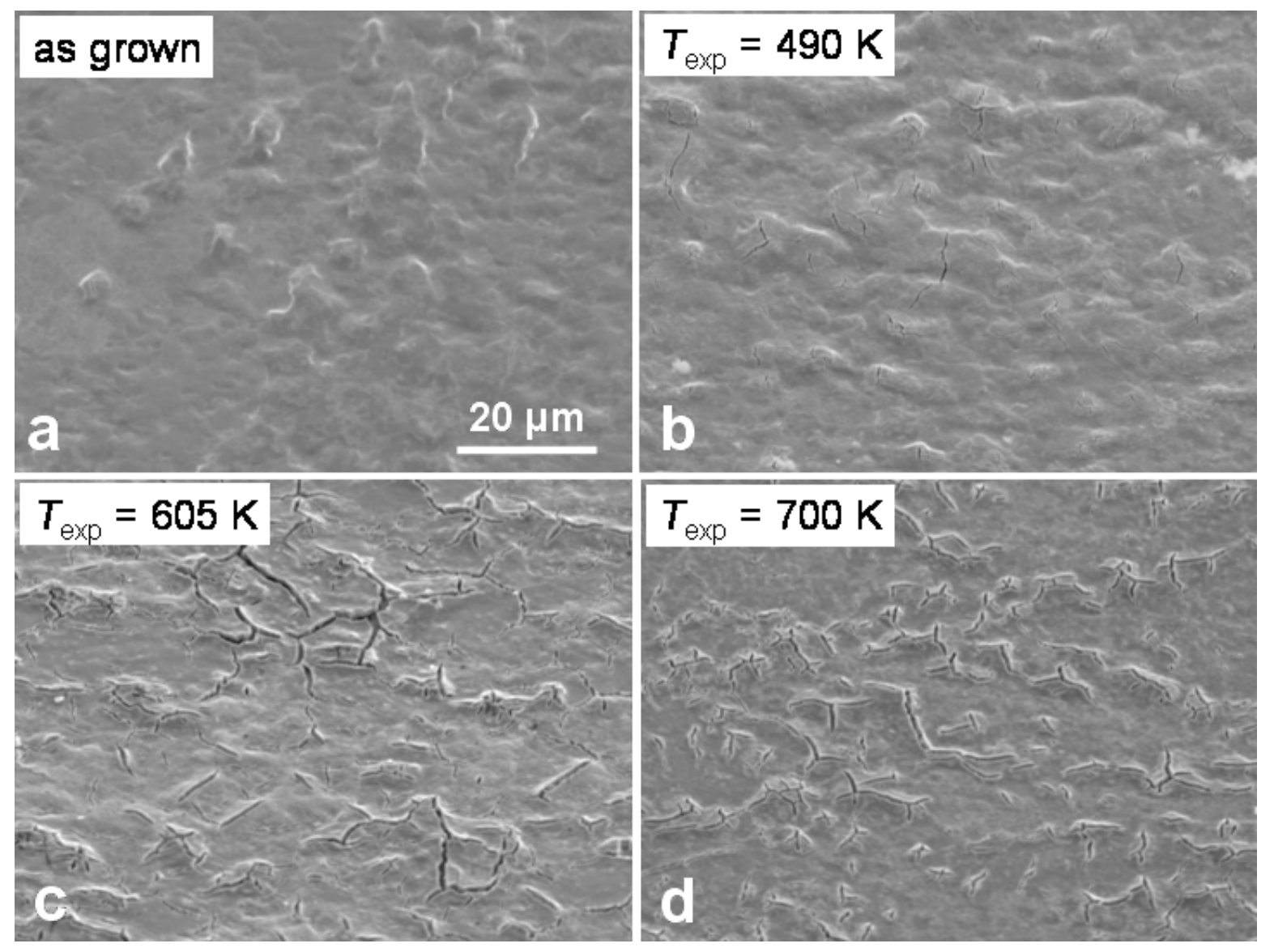

Figure 3. SEM images of tungsten oxide layers grown on the surface of polycrystalline ITER-grade $\mathrm{W}$ before (a) and after exposure to a low-energy (38 eV/D), high-flux $\left(10^{22}\right.$ $\mathrm{D} / \mathrm{m}^{2} \mathrm{~s}$ ) D plasma with an ion fluence of $10^{26} \mathrm{D} / \mathrm{m}^{2}$ at temperatures of $490 \mathrm{~K}(\mathrm{~b}), 605 \mathrm{~K}$ (c), and $700 \mathrm{~K}(\mathrm{~d})$. The magnification of all images is the same. 


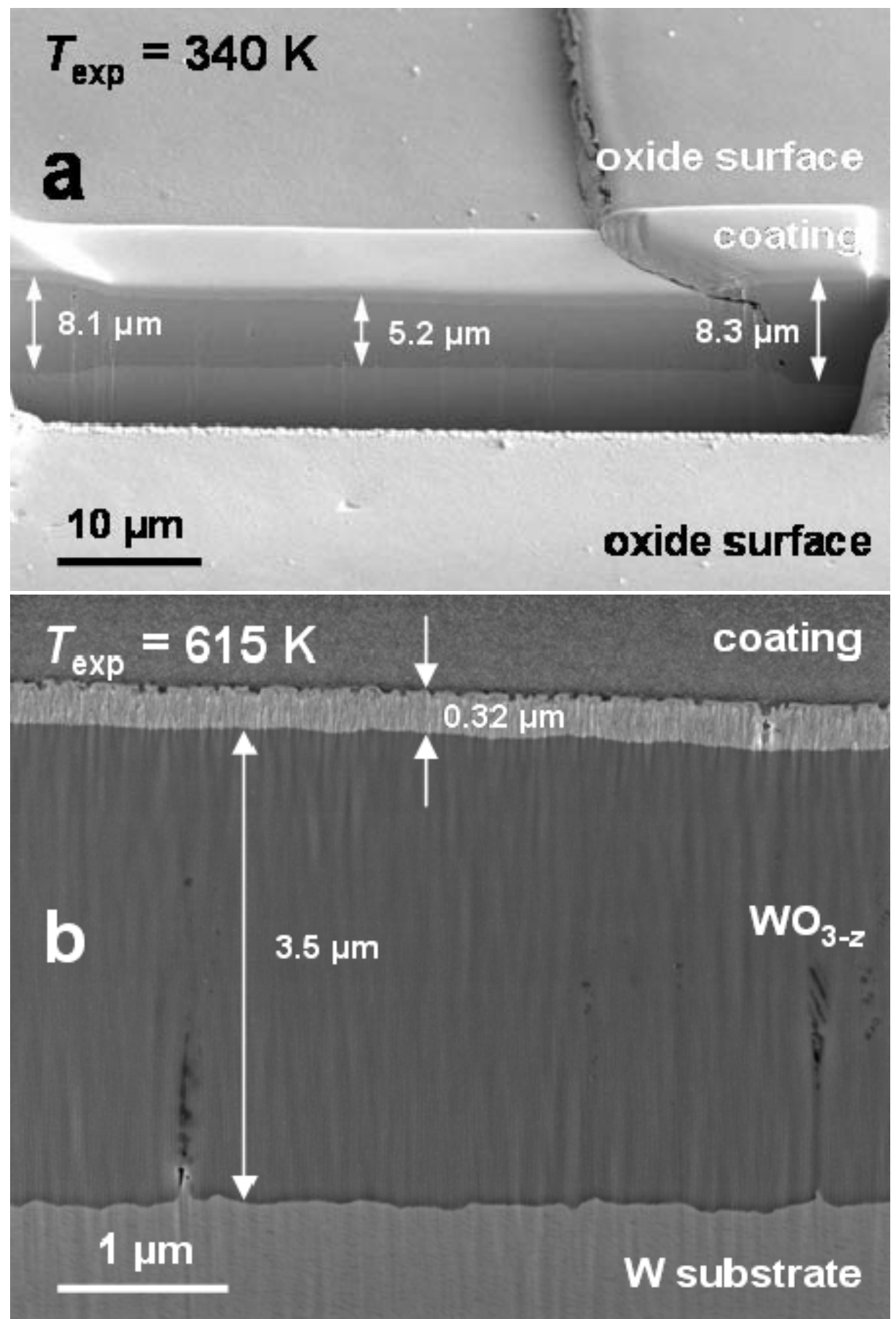

Figure 4. SEM images of tungsten oxide layers grown on the surface of recrystallized W and exposed to a low-energy (38 eV/D), high-flux $\left(10^{22} \mathrm{D} / \mathrm{m}^{2} \mathrm{~s}\right) \mathrm{D}$ plasma with an ion fluence of $10^{26} \mathrm{D} / \mathrm{m}^{2}$ at temperatures of $340 \mathrm{~K}$ (a) and $615 \mathrm{~K}$ (b). The central part of the images shows a cross-section prepared by FIB ( $-38^{\circ}$ tilted). In the panel (a), the thicknesses of $\mathrm{WO}_{3-z}$ layers on individual $\mathrm{W}$ grains are labelled; the upper and lower part of the image shows the surface $\left(52^{\circ}\right.$ tilted). Note the layer on top of the oxide is an artificial protection coating for preparing the cross-section. In the panel (b), the thicknesses of $\mathrm{WO}_{3-\mathrm{z}}$ layer and reduced oxide layer are labelled. 

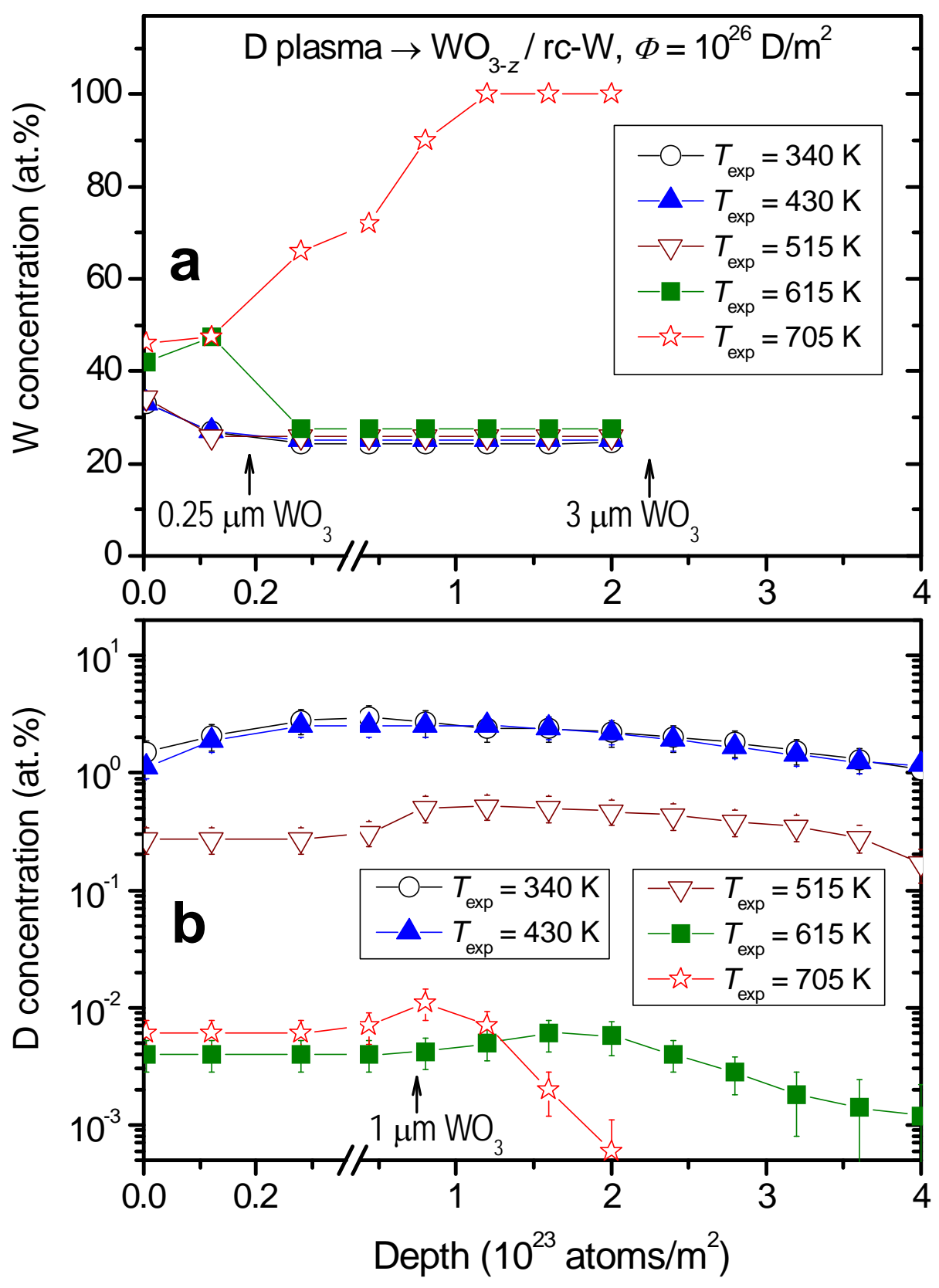

Figure 5. Tungsten (a) and deuterium (b) concentrations in tungsten oxide layers grown on the surface of recrystallized $\mathrm{W}$ and then exposed to a low-energy ( $38 \mathrm{eV} / \mathrm{D})$, high-flux $\left(10^{22} \mathrm{D} / \mathrm{m}^{2} \mathrm{~s}\right) \mathrm{D}$ plasma with an ion fluence of $10^{26} \mathrm{D} / \mathrm{m}^{2}$ at various temperatures. The tungsten concentration was determined by RBS, whereas the D concentration was measured by means of the $\mathrm{D}\left({ }^{3} \mathrm{He}, \mathrm{p}\right)^{4} \mathrm{He}$ nuclear reaction. Arrows indicate depths of $0.25,1$, and $3 \mu \mathrm{m}$ for stoichiometric $\mathrm{WO}_{3}$ taking the atomic density of $7.5 \times 10^{28}(\mathrm{~W}+\mathrm{O}) / \mathrm{m}^{3}$. 

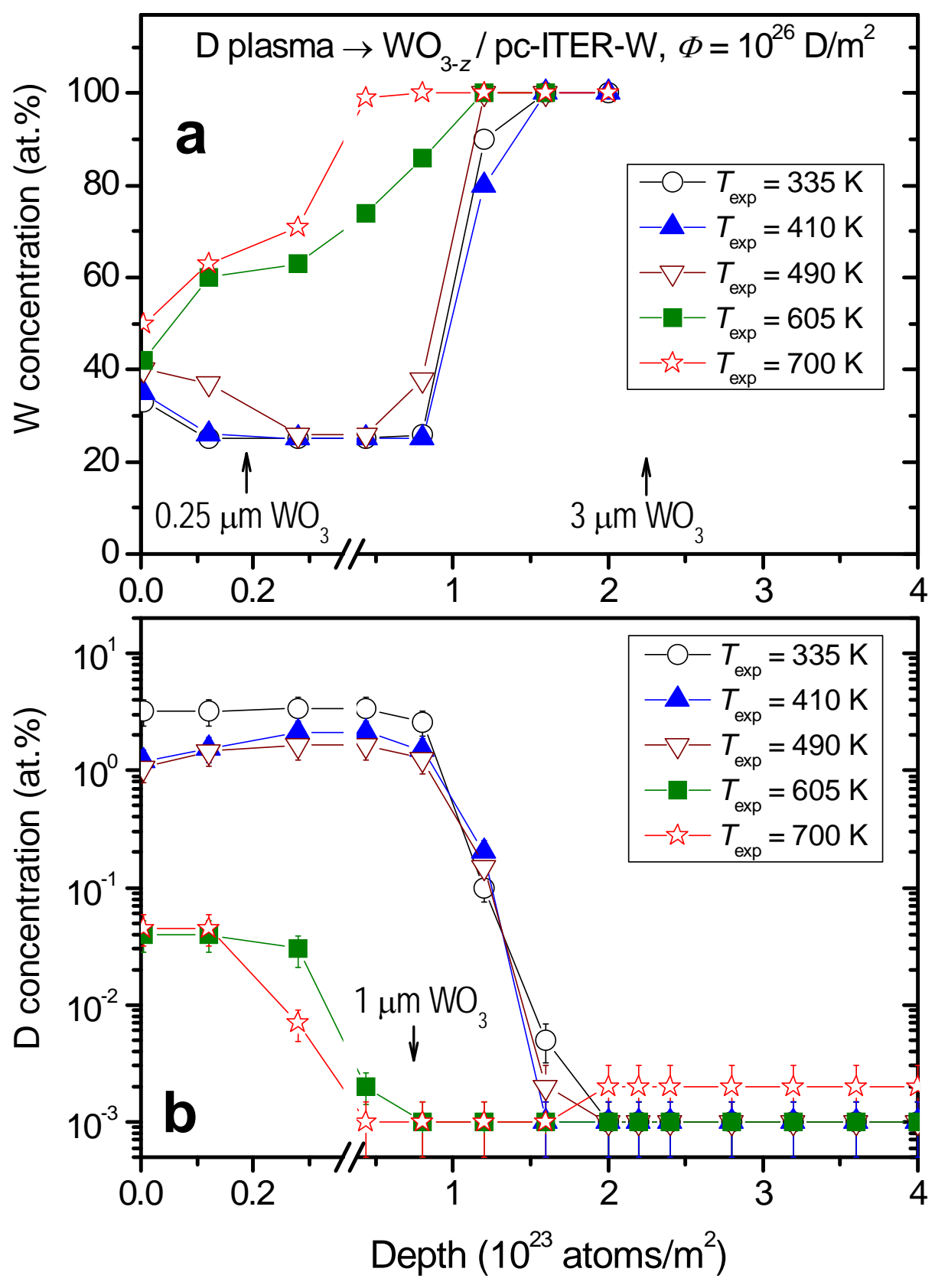

Figure 6. Tungsten (a) and deuterium (b) concentrations in tungsten oxide layers grown on the surface of polycrystalline ITER-grade $\mathrm{W}$ and then exposed to a low-energy (38 eV/D), high-flux $\left(10^{22} \mathrm{D} / \mathrm{m}^{2} \mathrm{~s}\right) \mathrm{D}$ plasma with an ion fluence of $10^{26} \mathrm{D} / \mathrm{m}^{2}$ at various temperatures. The tungsten concentration was determined by RBS, whereas the D concentration was measured by means of the $\mathrm{D}\left({ }^{3} \mathrm{He}, \mathrm{p}\right)^{4} \mathrm{He}$ nuclear reaction. Arrows indicate depths of $0.25,1$, and $3 \mu \mathrm{m}$ for stoichiometric $\mathrm{WO}_{3}$ taking the atomic density of $7.5 \times 10^{28}(\mathrm{~W}+\mathrm{O}) / \mathrm{m}^{3}$. 


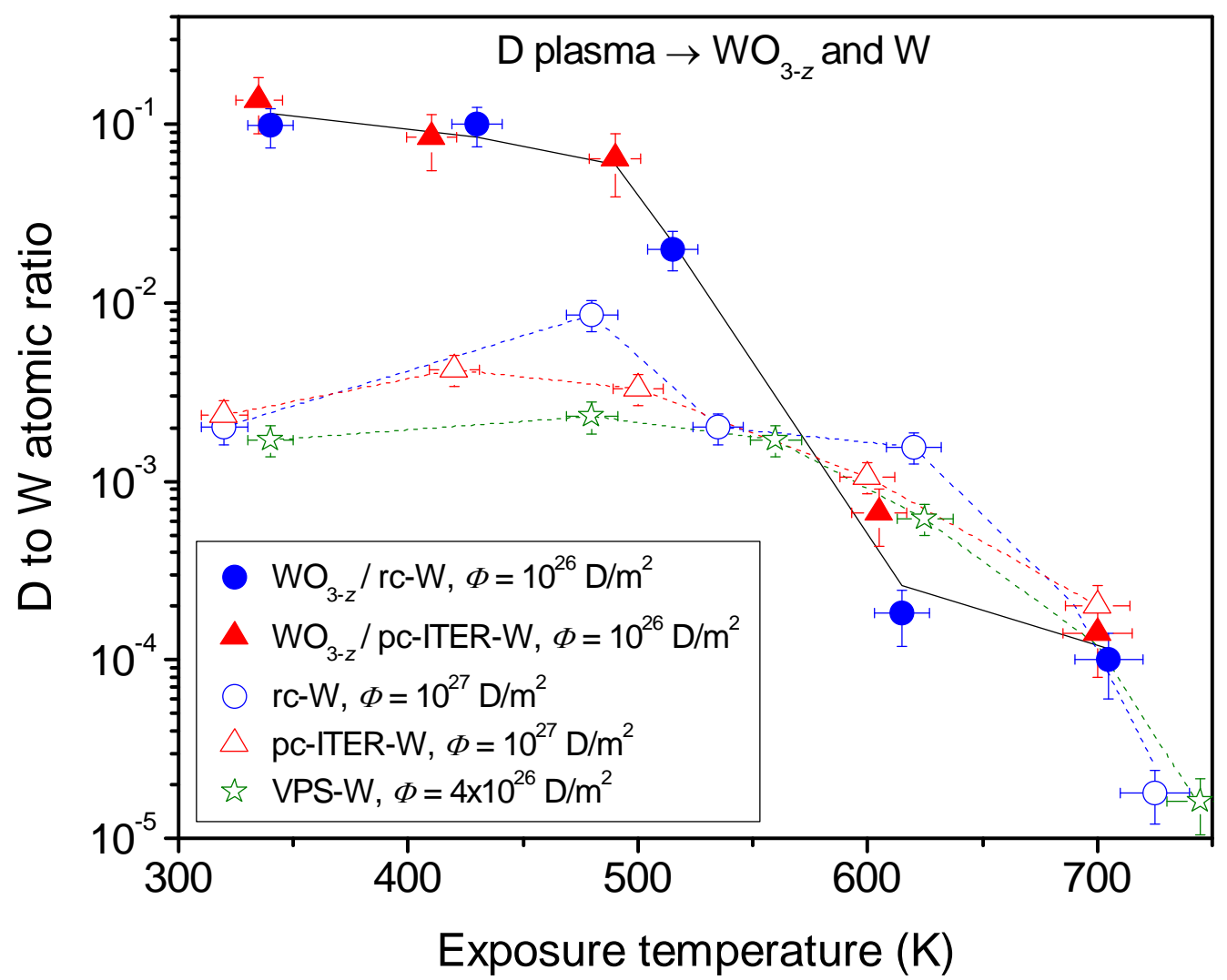

Figure 7. Maximum concentration of deuterium retained at a depth of 0.3-3 $\mu \mathrm{m}$ in tungsten oxide, recrystallized W (rc-W) [33], polycrystalline ITER-grade W (pc-ITER-W) [34], and porous vacuum plasma-sprayed W (VPS-W) [35] exposed to a low-energy (38 eV/D), high-flux $\left(10^{22} \mathrm{D} / \mathrm{m}^{2} \mathrm{~s}\right) \mathrm{D}$ plasma, as a function of the exposure temperature. The $\mathrm{D}$ concentration is expressed in units of the $\mathrm{D}$-to-W ratio. The applied $\mathrm{D}$ ion fluences, $\Phi$, are indicated in the legend. The $\mathrm{D}$ concentration in the $\mathrm{W}$ materials was taken after $\mathrm{D}$ plasma exposure to highest realized $\mathrm{D}$ ion fluences just to show maximum $\mathrm{D}$ concentration. 


\section{References}

[1] K. Sugiyama, M. Mayer, V. Rohde, M. Balden, Th. Dürbeck, A. Hermann, S. Lindig, A. Wiltner, H.W. Müller, R. Neu, the ASDEX Upgrade team, Nucl. Fusion 50(2010) 035001 .

[2] G. Federici, P. Andrew, P. Barabaschi, J. Brooks, R. Doerner, A. Geier, A. Herrmann, G. Janeschitz, K. Krieger, A. Kukushkin, A. Loarte, R. Neu, G. Saibene, M. Shimada, G. Strohmayer, M. Sugihara, J. Nucl. Mater. 313-316 (2003) 11.

[3] K. Nakamura, M. Hasegawa, F. Wang, S. Kawasaki, H. Nakashima, A. Higashijima, K.N. Sato, H. Zishi, K. Hanada, M. Sakamoto, H. Idei, Fusion Eng. Des. 83 (2008) 236.

[4] G. Ritz, T, Hirai, P. Norajitra, J. Reiser, R. Giniyatulin, A. Makhankov, I. Mazul, G. Pinchuk, J. Linke, Phys. Scripta T 138 (2009) 014064.

[5] C.H. Skinner, A.A. Haasz, V.Kh. Alimov, N. Bekris, R.A. Causey, R.E.H. Clark, J.P. Coad, J.W. Davis, R.P. Doerner, M. Mayer, A. Pisarev, J. Roth, T. Tanabe, Fusion Sci. Technol. 54 (2008) 891.

[6] J. Roth, J. Bohdansky, W. Ottenberger, Data on Low Energy Light Ion Sputtering, Report IPP 9/26 (Max-Planck-Institut für Plasmaphysik, Garching, 1979).

[7] S. Nagata, K. Takahiro, Phys. Scripta T94 (2001) 106.

[8] V.Kh. Alimov, V.M. Sharapov, A.E. Gorodetsky, Phys. Scripta T103 (2003) 72.

[9] N. Matsunami, N. Ohno, M. Tokitani, J. Nucl. Mater. 390-391 (2009) 693.

[10] A. Inouye, S. Yamamoto, S. Nagata, M.Yishikawa, T. Shikawa, Nucl. Instr. and Meth. B 267 (2009) 1480.

[11] D. Schneider, Oxidation von Wolfram in Sauerstoff und $\mathrm{O}_{2}$-haltigen Gasgemischen, in: Gmelin Handbuch der Anorganischen Chemie, Wolfram, Ergänzungsband B1, Die Systeme mit Edelgasen, Wasserstoff und Sauerstoff (Springer, Berlin, 1978) pp. 143170 (in German).

[12] R.D. Bringans, H. Höchst, H.R. Shanks, Surface Sci. 111 (1981) 80.

[13] P.J. Wiseman, P.G. Dickens, J. Solid State Chem. 6 (1973) 374.

[14] M.V. Šušic, Yu.M. Solonin, J. Mater. Sci. 23 (1988) 267.

[15] B.W. Faughnan, R.S. Crandall, M.A. Lampert, Appl. Phys. Lett. 27 (1975) 275.

[16] B. Reichman, A.J. Bard, D. Laser, J. Electrochem. Soc. 127 (1980) 647.

[17] P.G. Dickens, S.J. Hibble, R.H. Jarman, J. Electron. Mater. 10 (1981) 999.

[18] J.-R. Randin, R. Viennet, J. Electrochem. Soc. 129 (1982) 2349.

[19] Á. Vértes, R. Schiller, J. Appl. Phys. 54 (1983) 199.

[20] N.L. Hitchman, Thin Solid Films 61 (1979) 341. 
[21] Gmelin Handbuch der Anorganischen Chemie, Wolfram, Ergänzungsband B2, Oxides (Springer, Berlin, 1979) pp. 168-180 (in German).

[22] E. Salje, A.F. Carley, M.W. Roberts, J. Solid State Chem. 29 (1979) 237.

[23] R.D. Bringans, H. Höchst, H.R. Shanks, Phys. Rev. B 24 (1981) 3481.

[24] ASTM B0760-07 - Standard Specification for Tungsten Plate, Sheet, and Foil, ASTM International, West Conshohocken, PA, DOI: 10.1520/B0760-07, www.astm.org.

[25] S. Lindig, M. Balden, V.Kh. Alimov, T. Yamanishi, W.M. Shu, J. Roth, Phys. Scr. T 138 (2009) 014040.

[26] G.-N. Luo, W.M. Shu, H. Nakamura, S. O’Hira, M. Nishi, Rev. Sci. Instrum. 75 (2004) 4374.

[27] M. Mayer, SIMNRA User's Guide, Tech. Rep. IPP 9/113, Max-Planck-Institut für Plasmaphysik, Garching, 1997.

[28] V.Kh. Alimov, M. Mayer, J. Roth, Nucl. Instr. and Meth. B 234 (2005) 169.

[29] M. Mayer, E. Gauthier, K. Sugiyama, U. von Toussaint, Nucl. Instr. and Meth. B 267 (2009) 506

[30] E. Lassner and W.D. Schubert, Tungsten: Properties, Chemistry, Technology of the Element, Alloys, and Chemical Compounds (Kluwer Academic/Plenum, New York, 1999) p. 86.

[31] W. Eckstein, Computer Simulation of Ion-Solid Interaction, Springer Series in Materials Science, Vol. 10 (Springer, Berlin, 1991).

[32] J.O. Hougen, R.R. Reeves, G.G. Mannela, Ind. Eng. Chem. 48 (1956) 318.

[33] V.Kh. Alimov, W.M. Shu, J. Roth, K. Sugiyama, S. Lindig, M. Balden, K. Isobe, T. Yamanishi, Phys. Scripta T 138 (2009) 014048.

[34] V.Kh. Alimov, B. Tyburska, J. Roth (unpublished data)

[35] V.Kh. Alimov, B. Tyburska, O.V. Ogorodnikova, J. Roth, K. Isobe, T. Yamanishi, Proc. $19^{\text {th }}$ Intern. Conf. on Plasma Surface Interactions, San Diego, USA, May 24-28, 2010 (submitted to J. Nucl. Mater). 